\title{
What promotes and hinders success in breastfeeding in hospital care? - the role of social support and anxiety
}

\section{BACKGROUND}

Hospital stay is associated with difficult circumstances, which may be accompanied by anxiety. Difficulty with initiation and continuation of breastfeeding may be commonly experienced in the hospital. Observed difficulties can be modified by sharing knowledge and involvement of midwives in the care of mothers and newborns. Breastfeeding is considered to be the ideal choice of nutrition and infant's feeding, providing many benefits both for infants and their mothers. The aim of the study is to explore the role of the quality of breastfeeding assistance during delivery hospitalization and maternal anxiety for overall breastfeeding duration.

\section{PARTICIPANTS AND PROCEDURE}

The study included 858 women after labor from intentionally selected hospitals of Pomerania, discharged from hospital up to 15 days after birth. We used a questionnaire to collect data on the nursing assistance and the process of breastfeeding during patients' stay in a hospital. In addition, we applied the State-Trait Anxiety Inventory (STAI) to measure the levels of state and trait anxiety.

\section{RESULTS}

The results showed a significant relationship between the level of maternal postpartum anxiety and duration of breastfeeding. Mothers (mostly after physiological labor) reported a significantly lower level of state anxiety in hospitals titled Baby Friendly. Additionally, a significant difference in breastfeeding duration depending on the hospital and mothers' perception of receiving support from midwives was found.

\section{CONCLUSIONS}

It is reasonable to continue the activities increasing standards of medical personnel support and raising the midwives' and mothers' awareness of the importance of anxiety for breastfeeding duration.

\section{KEY WORDS}

breastfeeding; anxiety; infant; mother; medical staff

Organisation - 1: Department of Obstetrics, Medical University of Gdansk, Gdansk, Poland · 2: Department of Psychology of Development and Education, University of Warmia and Mazury, Olsztyn, Poland · 3: Institute of Psychology, University of Gdansk, Gdansk, Poland · 4: Public Health and Social Medicine Department, Medical University of Gdansk, Gdansk, Poland

Authors' Contributions - A: Study design · B: Data collection · C: Statistical analysis · D: Data interpretation · E: Manuscript preparation · F: Literature search · G: Funds collection

CORRESPONDING AUthor - Justyna Michałek-Kwiecień, Ph.D., Department of Psychology of Development and Education, University of Warmia and Mazury in Olsztyn, 2 Oczapowskiego Str., 10-719 Olsztyn, Poland, e-mail: justyna.michalek@uwm.edu.pl 


\section{BACKGROUND}

Modern standards of medical interventions are derived from practical medicine, which is continuously developing thanks to reliable research and articles - this is called evidence-based medicine (EBM). Prominent professional organizations such as WHO and UNICEF (1989), the American Academy of Pediatrics (Gartner et al., 2005) and the Academy of Breastfeeding Medicine (Chantry, Eglash, \& Labbok, 2005) recommend breastfeeding as an optimal source of food, ensuring appropriate physical, emotional and mental development of a child (Gartner et al., 2005; Nehring-Gugulska \& Żukowska-Rubik, 2006; Stuebe \& Schwarz, 2010). At the same time, abundant scientific research confirms that the competent care of a mother and a child, from the first hours of a child's life (which largely takes place in obstetric wards), promotes stimulation of lactation and helps to avoid problems related to lactation which often discourage mothers and hinder breastfeeding (Bigelow et al., 2014; Grassley \& Nelms, 2008; Haroon, Das, Salam, Imdad, \& Bhutta, 2013; Mathews, Leerkes, Lovelady, \& Labban, 2014; Spatz, Kim, \& Froh, 2014; Spiby et al., 2009).

The latest scientific research proves the positive impact of breastfeeding on health status of newborns and infants. This is a natural stage in life both of a woman and a child. During pregnancy a mother and a child build a harmonized oneness. The mother's body protects, nourishes and stimulates development of a child. After labor breastfeeding becomes a natural extension of this relation (Bigelow et al., 2014; Tambelli, Odorisio, \& Lucarelli, 2014). The type of infant feeding chosen - natural or artificial - can undoubtedly affect the quality of the emotional bond between a mother and a child. This is a result of differences in behavior of a mother and a child during and between feedings dependent on the type of feeding (breast or bottle feeding) and type of food (female or synthetic milk) (Kielbratowska, Kazmierczak, Michalek, \& Preis, 2015; Taki et al., 2010). Natural and artificial feeding satisfy the needs of a baby and a mother in different ways and provide various sensory cues. During breastfeeding the infant receives distinct visual, tactile and olfactory stimuli, while the mother learns what her infant is doing through direct sensory feedback (Jansen, de Weerth, \& Riksen-Walraven, 2008).

Optimally, breastfeeding should begin as soon as possible after birth when a child is placed on a mother's chest and is touching her body. The first attempt should not be undertaken later than 2 hours after labor (Phillips, 2013). The experience can be of course positive, resulting in long breastfeeding, but can also be negative, resulting in quick abandonment. Breastfeeding is a source of various emotional and cognitive experiences. Therefore, breastfeeding mothers dedicate more time and attention to their children and feel more self-confident (Bigelow et al., 2014; Kielbratowska, Kazmierczak, Michalek, \& Preis, 2015). Breastfeeding releases positive symptoms of emotional behavior that create an emotional bond with a newborn baby, extremely important for the further proper development of a child (Bielawska-Batorowicz, 2006; Tambelli, Odorisio, \& Lucarelli, 2014).

The obstacles in starting and continuing breastfeeding are usually observed when a mother and a child are still in hospital - first in the delivery room, later on obstetric wards - and depend on sharing knowledge and engagement of obstetric personnel (Dunn et al., 2015; Norris-Grant \& Jaggers, 2014). Hospital factors which influence breastfeeding negatively include mother-infant separation (Bystrova et al., 2007), cesarean delivery (Kushnir, Friedman, Ehrenfeld, \& Kushnir, 2012; Nissen et al., 1996), uncontrolled postpartum pain (Karlström, Engström-Olofsson, Norbergh, Sjöling, \& Hildingsson, 2007) and use of supplements (Bystrova et al., 2007). Hospitalization can cause anxiety which can manifest as a sense of concern, feeling of tension, embarrassment, or threat (Sęk, Ścigała, Beisert, \& Bleja, 1992) and in the perinatal period may be a symptom of depression in women (Bidzan, 2013; Kaźmierczak, 2015; Podolska et al., 2010). Anxiety might be a cause of reduced exclusivity and continuation of breastfeeding due to delayed milk production, which might further increase stress of the mother (Adedinsewo et al., 2014). Anxiety is a very important variable in both the theory and practice of psychology. There are many evaluation methods using different questionnaires that allow assessment of the level and type of anxiety. A fast and simple interpretation method is an inventory made by C.D. Spielberger called the State-Trait Anxiety Inventory (STAI) (Sosnowski, 1977; Wrześniewski, Sosnowski, \& Matusik, 2002). The inventory consists of two subscales called scales X-1 and X-2, assessing two types of anxiety based on separate approaches to this problem. Anxiety as a psychological state (hereinafter called "S-Anxiety") is understood by Spielberger (Sosnowski, 1977; Wrześniewski, Sosnowski, \& Matusik, 2002) as a current, changeable emotional condition of a person experienced subjectively as tension and fear, accompanied by increased activity of the autonomic nervous system (Sosnowski, 1977; Wrześniewski, Sosnowski, \& Matusik, 2002). The characteristic feature of this condition is high variability under the influence of various threatening and stressful factors. This can be called reactive anxiety. It is high in situations perceived as carrying risk regardless of the objective circumstances. The second subscale is the Trait Anxiety Scale (measuring "T-Anxiety"). This scale evaluates an element or a behavioral disposition which makes a person susceptible to the perception of a wide range of objectively harmless situations as threatening. People respond to
Breastfeeding and hospital care 
them with disproportional anxiety in relation to the objective danger. The characteristic feature of this condition is its stability in time. This can be called chronic anxiety (Sosnowski, 1977; Wrześniewski, Sosnowski, \& Matusik, 2002).

The mentioned concept of anxiety understood as state and trait is also used for description of behavior of mothers in the postnatal situation in the context of lactation. There are known studies which prove that mothers who have a high level of S-Anxiety in the STAI Inventory and who are not breastfeeding show less sensitivity to the needs of their children within six months after birth, which may result in increased negative emotionality of their 18-month-old infants (Jonas et al., 2015). S-Anxiety is also a strong predictor (in addition to concerns about not having enough milk) of continuing breastfeeding within two weeks and six months after labor (Flaherman, Beiler, Cabana, \& Paul, 2015). Different studies also indicate that an increase in results on the scales of S-Anxiety and T-Anxiety within three months after childbirth reduces the chances of continuation of breastfeeding at 12 months after labor (Adedinsewo et al., 2014).

Mothers who suffer from anxiety and fear most often experience major difficulties in the perinatal period. The reasons for anxiety can vary. Usually it can be determined as a general concern often related to childcare, fear about child's health condition and difficulties appearing during breastfeeding. Being frustrated and anxious is usually a result of the mother's high dependence on other people or fear of being left without help and loneliness (Rowu, 1995).

Pregnancy, labor and subsequently breastfeeding and childcare are periods which are related to higher risk of stress experienced by mothers (Bidzan, 2013; Dragan, 2014). The majority of women are so strongly focused on labor that they are not able to think forward about problems that will occur afterwards. Some women, especially those who are giving birth to their first child, are worried about having enough milk and being able to breastfeed. Such situations require reassuring a woman, giving her the most important information about lactation and support by medical personnel and close family members (Tsai, Huang, \& Lee, 2015). Many women expect that immediately after labor they will return to their usual activities. When it does not happen, they experience powerlessness due to numerous difficulties that they face in adjusting to the new circumstances (Janiuk, 2006; Rowu, 1995).

Emotional conditions are caused by complex reasons, of which the most common are:

- severe changes in the woman's body caused by pregnancy,

- after labor inhibition of production of hormones by the placenta, which is associated with production of breast milk,
- rapid appearance of milk, especially on the $3^{\text {rd }}$ and $4^{\text {th }}$ day after labor, which results in typical problems,

- lack of time for a mother and a child to get used to the new situation,

- the continuous need of a child to be fed, which makes the mother tired,

- the sense of isolation experienced by the mother, who feels distanced by other people who avoid her because they think that the only thing that matters for the young mother is a child,

- guilt arising from difficulties in meeting the expectations of the family including that the woman should be happy after giving birth (Golańska, 1994; Rowu, 2006).

The course of lactation and breastfeeding is an element of multidisciplinary medical care, which should be carried out by competent, friendly personnel knowing how to communicate properly. It is common that success in breastfeeding is dependent on the new mother being surrounded by competent and friendly people to assist her with overcoming difficulties (Haider, Chang, Bolton, Gold, \& Olson, 2014).

The aim of this study was to assess the associations between female perception of support given by medical personnel during the perinatal period, length of breastfeeding, including the time of exclusive breastfeeding, and anxiety experienced by the hospitalized women.

\section{PARTICIPANTS AND PROCEDURE}

Eight hundred and fifty eight women from 5 selected hospitals in Pomerania, Poland were surveyed within 15 days of hospital discharge. Permission to carry out the study was obtained from the Independent Bioethics Commission for Research of the Medical University of Gdansk, NKEBN/459/2004. Hospitals were selected taking into consideration different standards in provision of lactation support by medical personnel in relation to the 'Ten Steps' to successful breastfeeding program (Baby Friendly Hospital Initiative) (WHO/ UNICEF, 1989). The study included those hospitals that deal mostly with physiological labors $(2,3,4)$, and those that provide regular monitoring of pregnancy $(1,5)$ :

1. Hospital without the Baby-Friendly Hospital title.

2. Hospital with the Baby-Friendly Hospital title.

3. Hospital without the Baby-Friendly Hospital title.

4. Hospital with the Baby-Friendly Hospital title.

5. Hospital with the Baby-Friendly Hospital title.

The study included women who met all the criteria mentioned below:

- had a full-term pregnancy,

- gave birth to a child with weight of at least 2500 grams,

- gave birth to a child without any disorders of neonatal period (birth defects, adjustment disorders etc.), 
- were discharged from hospital within 15 days after labor (the participants were interviewed on days 2-3 after delivery; for some women the longer length of hospital stay was due to newborn hospitalization).

One thousand questionnaires were distributed among randomly selected women. The questionnaire consisted of questions related to nursing assistance according to the 'Ten Steps' to successful breastfeeding - WHO recommendations (WHO/UNICEF, 1989, 1992) (e.g. Have you been assisted with breastfeeding after delivery?, Who supported you with breastfeeding during your hospital stay?) as well as the history of breastfeeding (e.g. Is the baby still breastfed?, If not, when did you stop breastfeeding [in what month]?).

The respondents filled out correctly 898 questionnaires, and 40 were filled out partially. After obtaining consent, the questionnaires were filled out by women after labor with the help of medical personnel (mostly nurses, midwives or neonatologists). The mean age of respondents was $27.9(S D=5.05)$.

Additionally, 317 randomly selected women were asked to fill out the STAI questionnaire, which is a widely used measure of state and trait anxiety, with good reliability and validity (Spielberger, Gorsuch, \& Lushene, 1970; Wrześniewski, Sosnowski, \& Matusik, 2002). The STAI has 20 items for assessing state anxiety (X-1 scale) (measures the subjective feelings of apprehension, nervousness and anxiety at a given moment) and 20 items for trait anxiety (X-2 scale) (measures ongoing chronic subjective feelings of apprehension, nervousness and anxiety). All items are rated on a 4-point scale (e.g., from almost never to almost always). Women from this group were questioned once again after one year to determine the course of feeding, especially in terms of duration of breastfeeding. Children of mothers from this group breastfed on average for 7 months $(S D=4.30)$. Exclusive breastfeeding lasted on average for 4 months $(S D=2.24)$. No categories of breastfeeding duration were created. Exclusive breastfeeding lasted from 1 to 7 months. The procedure resulted from the need to respect precise details of the length of breastfeeding.

\section{STATISTICAL ANALYSES}

Data were analyzed using Statistical Package for the Social Sciences (SPSS) version 21.0 (SPSS Inc., license purchased by the University of Gdansk). Summary statistics and answers given by women in terms of receiving support from medical personnel were reported as frequencies and percentages. Collected data on duration of breastfeeding had non-normal distribution; therefore, in order to determine if there is a relation between level of anxiety in the perinatal period and duration of breastfeeding, Spearman's rank correlation test was used. The level of significance was
Table 1

Summary of demographic characteristics

\begin{tabular}{|c|c|}
\hline Demographic characteristic & $n(\%)$ \\
\hline All subjects $(n)$ & 858 \\
\hline \multicolumn{2}{|l|}{ Age (years) } \\
\hline$<21$ & $53(6.2)$ \\
\hline $21-25$ & $224(26.1)$ \\
\hline $26-30$ & $344(40.1)$ \\
\hline $31-35$ & $167(19.5)$ \\
\hline $36-40$ & $60(7)$ \\
\hline$>40$ & $9(1)$ \\
\hline Unanswered & $1(0.1)$ \\
\hline \multicolumn{2}{|l|}{ Marital status } \\
\hline Married & $665(77.5)$ \\
\hline Single & $115(13.4)$ \\
\hline Divorced & $21(2.4)$ \\
\hline Widowed & $1(0.1)$ \\
\hline Cohabiting & $56(6.5)$ \\
\hline \multicolumn{2}{|l|}{ Education } \\
\hline Primary school & $62(7.2)$ \\
\hline Vocational school & $161(18.7)$ \\
\hline High school & $321(37.4)$ \\
\hline Bachelor's degree or higher & $314(36.6)$ \\
\hline \multicolumn{2}{|l|}{ Employment } \\
\hline Yes & $523(61)$ \\
\hline No & $40(4.7)$ \\
\hline Casual work & $293(34.1)$ \\
\hline Unanswered & $2(0.2)$ \\
\hline \multicolumn{2}{|l|}{ Attending antenatal classes } \\
\hline Yes & $221(25.8)$ \\
\hline No & $637(74.2)$ \\
\hline \multicolumn{2}{|c|}{ Planned duration of breastfeeding (months) } \\
\hline$<4$ & $17(2)$ \\
\hline $4-6$ & $263(30.7)$ \\
\hline $7-12$ & $419(48.8)$ \\
\hline$>12$ & $80(9.3)$ \\
\hline Unanswered & $79(9.2)$ \\
\hline \multicolumn{2}{|c|}{ Source of knowledge about breastfeeding } \\
\hline Antenatal classes & $46(5.4)$ \\
\hline Books & $499(58.2)$ \\
\hline Without preparation & $250(29.1)$ \\
\hline $\begin{array}{l}\text { Other (including friends and } \\
\text { family members, previous } \\
\text { experiences) }\end{array}$ & $43(5)$ \\
\hline Unanswered & $20(2.3)$ \\
\hline
\end{tabular}

Breastfeeding and hospital care 


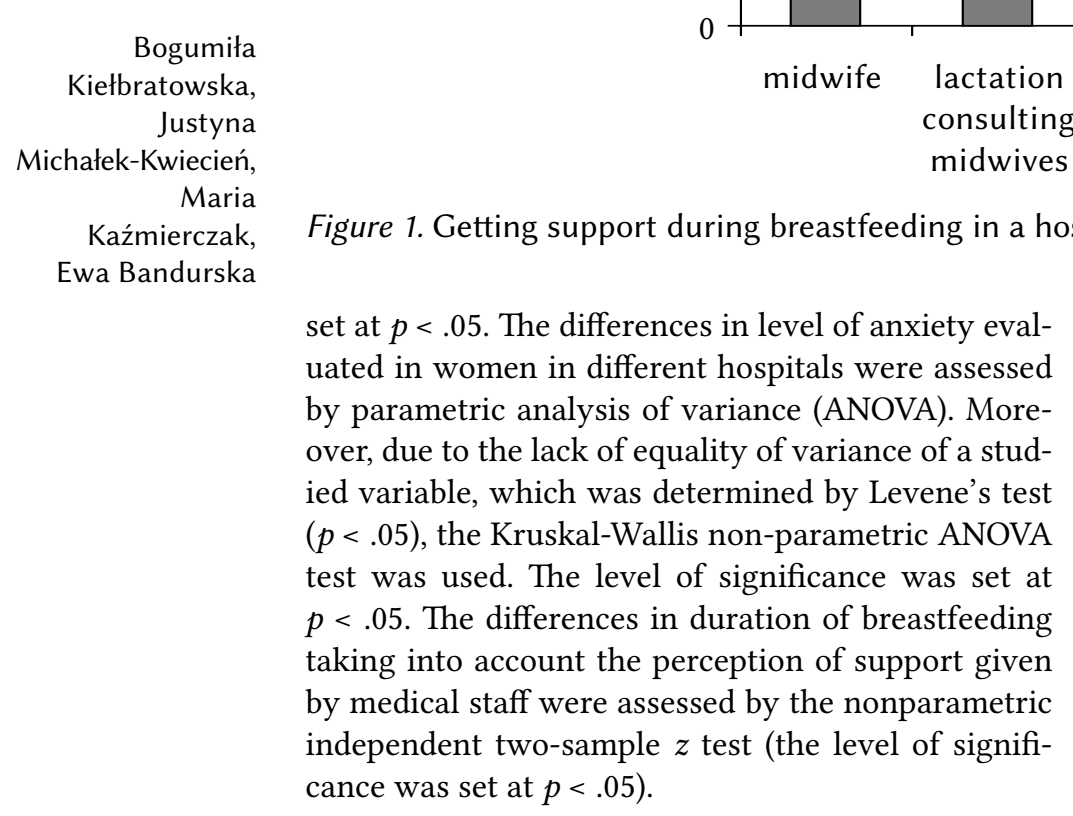

\section{RESULTS}

The characteristics of the participants are summarized in Table 1 . The sample was composed primarily of women who were married (77.50\%), on average 27.9 years old, ranging from 17 to 47 years and had a high school $(37.40 \%)$ or university diploma $(36.60 \%)$. The majority of the respondents were employed $(61.00 \%)$. Approximately $26.00 \%$ of the mothers reported participation in antenatal classes. Most women stated that they wanted to breastfeed ( $48.80 \%$ of mothers planned to breastfeed for 7-12 months, $39.70 \%$ for 4-6 months).

\section{Table 2}

Level of anxiety and duration of breastfeeding and duration of exclusive breastfeeding (Spearman's rank correlation coefficient, two-tailed test of significance)

\begin{tabular}{lcc}
\hline Variable & \multicolumn{2}{c}{ Correlation coefficient } \\
\cline { 2 - 3 } & Breastfeeding & $\begin{array}{c}\text { Exclusive } \\
\text { breastfeeding }\end{array}$ \\
\hline State anxiety & $-.61^{* * *}$ & $-.60^{* * *}$ \\
Trait anxiety & $-.35^{* * *}$ & $-.26^{* * *}$ \\
\hline
\end{tabular}

Note. Breastfeeding and exclusive breastfeeding are continuous variables. ${ }^{* * *} p<.001$.
Before delivery, most women (58.20\%) obtained information about breastfeeding from books.

The authors proceeded with an analysis of answers given by women in terms of support received from medical personnel (midwives, nurses, doctors) during the first breastfeeding. The answer was given by $97.00 \%$ of respondents, out of whom $82.00 \%$ reported receiving such support during the first breastfeeding and $18.00 \%$ reported not receiving such help. Missing data are the result of the random lack of responses.

Figure 1 shows that breastfeeding was most commonly assisted by midwives on an obstetrics ward $(57.00 \%)$, lactation consulting midwives $(27.00 \%)$, family members $(4.00 \%)$ and others $(1.00 \%)$. Around $47.00 \%$ of women reported that in the next days after labor they felt a need to receive help from medical personnel, $22.00 \%$ of women did not need it, while $31.00 \%$ did not feel such need at all.

Additional analyses were conducted separately for each of the hospitals included in the study that reported implementing the 10 steps program or mostly dealing with physiological labors. It is important to mention that in the smallest hospital (2) a statistically significant relation was found between higher support perceived by mothers (and given midwives) and duration of breastfeeding (in the case of perceived support, $M=7.81, S D=3.80$; in the case of its lack, $M=6.49, S D=3.86, z=-1.97, p=.049$ ).

In the next step, the authors explored the associations between maternal anxiety and breastfeeding. The results presented in Table 2 indicate a correlation between the variables S-Anxiety, T-Anxiety and both duration of breastfeeding and duration of exclusive breastfeeding. Higher level of anxiety was related to shorter duration of breastfeeding (it was a continuous variable, and it was not modified in order to respect mothers' detailed responses). The relationship between S-Anxiety and duration of breastfeeding was found to be strong. The relationship between T-Anxiety and duration of breastfeeding was average and all associations between anxiety and exclusive breastfeeding were weak. 
Next, the differences in level of anxiety were evaluated in women using perinatal care in different hospitals. The results proved statistically significant differences between levels of S-Anxiety observed in different hospitals $(F=11.01, p<.001)$. The lowest level of state anxiety was observed among women who stayed in the Baby-Friendly Hospitals and had physiological labor. Detailed information on results of this analysis are presented in Table 3 and Figure 2. As expected, significant differences were not found in the value of T-Anxiety observed in women treated in the analyzed hospitals.

\section{DISCUSSION}

In Poland before the Second World War breastfeeding had become a common practice for all women having a small child. Breastfeeding had been a tradition passing from one generation to the next and a necessity expected by the support people surrounding the young mother, especially close family members (Kowalewski, 1993). Nowadays, labor conditions and type of feeding of infants have changed.

In the present study the perinatal situation in obstetrics wards has been analyzed, among other methods, by discussing factors related to success in breastfeeding. Natural feeding gives a child an op- portunity to build and optimally use the individual health potential (Mikiel-Kostyra, 2003).

The present study also included the analysis of environmental (hospital) and individual (anxiety) aspects in relation to standards of breastfeeding recommended by the World Health Organization (WHO) (1989), meaning exclusive breastfeeding through the first 6 months of a child's life, and then introducing new types of food with continuing breastfeeding for 2 years or longer. It has been observed that events related to labor and breastfeeding might cause an increased level of anxiety in women (it is more commonly observed in hospitals not having the Certificate of a "Baby-Friendly Hospital"), which is related to shorter duration of exclusive breastfeeding.

In different studies the authors mostly concentrate on procedures supporting breastfeeding. On the basis of those analyses, it has been proven that the course of lactation can be influenced by medical personnel giving support to women (Gartner et al., 2005; Hauck \& Irurita, 2003; Spatz, Kim, $\&$ Froh, 2014). The results obtained in the present study, focused on the mother's perception of support given by medical staff, seem to support the results published earlier by different authors dealing with breastfeeding. Women participating in this study have expressed the need to receive support from medical personnel during lactation. Still it is

Table 3

Significance of differences in the level of state anxiety among patients in various hospitals

\begin{tabular}{lccccc}
\hline Hospital & $\{1\} M=42.76$ & $\{2\} M=36.61$ & $\{3\} M=39.26$ & $\{4\} M=36.78$ & $\{5\} M=46.94$ \\
\hline$\{1\}$ & & .009 & $n s$ & .013 & ns \\
$\{2\}^{*}$ & .009 & & $n s$ & ns & $<.001$ \\
$\{3\}$ & ns & ns & & ns & $<.001$ \\
$\{4\}^{*}$ & .013 & ns & ns & & $<.001$ \\
$\{5\}^{*}$ & $\mathrm{~ns}$ & $<.001$ & $<.001$ & $<.001$ & \\
\hline
\end{tabular}

Note. $M$ - mean; ns - not significant. *The "Baby-Friendly" Certificate.

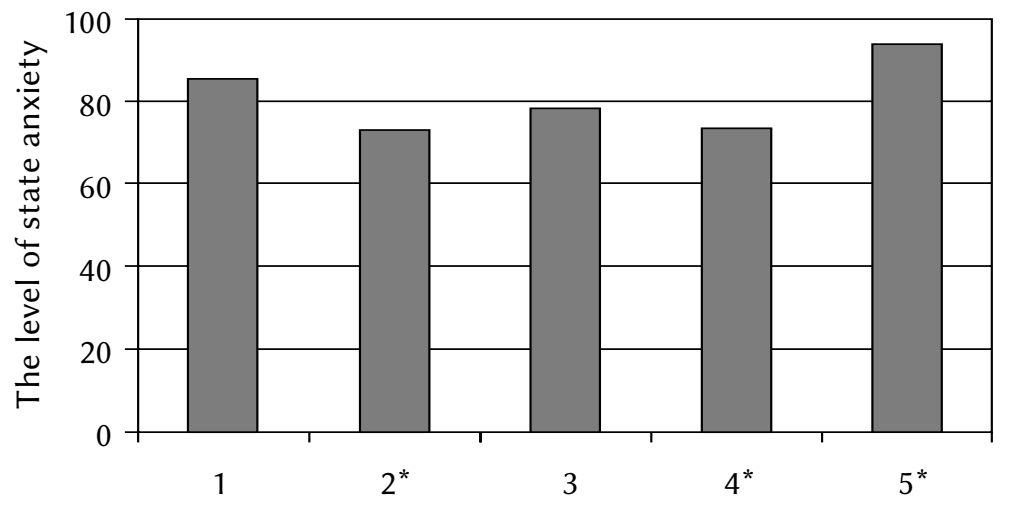

*The „Baby-Friendly” Certificate

Figure 2. Level of value of variable "S-Anxiety" among patients in the analyzed hospitals. 
worth noting that not all women in this study answered questions about support. Higher needs have been observed in women with an increased level of anxiety understood both as state and trait. The psychological analysis of functioning of families with newborns also indicates that assistance of medical personnel is required for supporting young parents in taking care of a newborn baby and adapting the family to a new situation (Kaźmierczak, Kiełbratowska, Lewandowska-Walter, Michałek, \& Błażek, 2012; Kaźmierczak, Kiełbratowska, Pastwa-Wojciechowska, \& Preis, 2013), which might be especially relevant in the case of mothers with an increased level of anxiety. It is worth adding that breastfeeding can be particularly important for women with increased anxiety because of its positive effect on relaxation as expressed through lowering blood pressure, skin-to-skin contact and higher secretion of oxytocin (Jonas et al., 2015). which supports building a relationship between the mother and her child. In the present study, the authors noted a statistically significant difference in levels of S-Anxiety between analyzed hospitals but no significant difference was noted in the T-Anxiety scores. It has been shown that only type of anxiety modified by current, changeable situation (in this case the hospital) seems to have a significant impact on the analyzed features. The highest level of anxiety was present in women hospitalized in hospitals that provide regular monitoring of pregnancy $(1,5)$ when compared to the hospital with the "Baby-Friendly Hospital" certificate (3). Lower levels of anxiety were observed in women hospitalized in two hospitals having "Baby-Friendly Hospital" certificates. This fact suggests that introducing recommendations of WHO (1992) regarding adherence to procedures favoring breastfeeding, additional training of medical personnel, and unification of procedures promoting breastfeeding (which is obligatory for certificated hospitals) benefits the sense of safety in women in the perinatal period (Haider et al., 2014; Pugh, Milligan, \& Brown, 2001).

Future studies should, as a result of observed relations, concentrate on time and personnel management on obstetrics wards, with special attention given to introducing standards recommended by WHO for perinatal care, including lactation counseling (Wen, Simpson, Rissel, \& Baur, 2012). Moreover, the problem should also be analyzed from the point of view of medical personnel, as this would allow providers to take psycho-social considerations and policies on obstetrics wards into consideration to optimize perinatal care. It is worth noting that the place of labor was not related to the stated level of T-Anxiety, which supports the idea of its stability and also seems to indicate that this feature might be a universal predictor of efficiency of breastfeeding.

\section{CONCLUSIONS}

The conducted study has led us to identify two contextual factors that contribute to better emotional functioning after labor and longer breastfeeding: the Ten Steps program in hospitals and perceived support from midwives. In the course of this study, on the basis of collected empirical data and statistical analyses the following conclusions can be drawn:

The role of the 'Ten Steps' to successful breastfeeding program implemented in hospitals can influence the reported level of anxiety in women after labor and subsequently duration of breastfeeding. The lowest level of anxiety defined as a state was observed in hospitals certified with a "Baby-Friendly Hospital" certificate and in hospitals in which more physiological births were observed.

The role of experienced support in breastfeeding has been noticed and appreciated by women. Most often support was given by midwives and relatives. In the smallest hospital, with a "Baby-Friendly Hospital" certificate, it has been proven that support given by midwives is the strongest factor influencing breastfeeding.

Due to the low prevalence of breastfeeding, based on analysis of the global trends in exclusive breastfeeding (Bigelow et al., 2014; Cai, Wardlaw, \& Brown, 2012; WHO, 2015), and even lower exclusive breastfeeding through the first six month of a child's life and continued for 1 year or longer, the American Academy of Pediatrics (AAP) - the section supporting breastfeeding - made a statement in which it was emphasized that the main cause of the low prevalence in breastfeeding is lack of encouragement, help and assistance made by doctors and the rest of the medical personnel (Eidelman, 2012).

\section{LIMITATIONS}

The study did not include repeated measurement of anxiety. In future studies it would be worth controlling for multiple factors that may affect anxiety level such as preparing women for childbirth, course of pregnancy, the circumstances associated with caesarean section, or delayed milk production.

\section{References}

Adedinsewo, D. A., Fleming, A. S., Steiner, M., Meaney, M. J., \& Girard, A. W.; MAVAN team. (2014). Maternal Anxiety and Breastfeeding: Findings from the MAVAN (Maternal Adversity, Vulnerability and Neurodevelopment) Study. Journal of Human Lactation, 30, 102-109.

Bidzan, M. (2013). Nastoletnie rodzicielstwo. Perspektywa psychologiczna [Teenage Parenthood. 
Psychological perspective]. Gdańsk: Harmonia Universalis.

Bielawska-Batorowicz, E. (2006). Psychologiczne aspekty prokreacji [Psychological aspects of procreation]. Katowice: „Śląsk” Wydawnictwo Naukowe.

Bigelow, A. E., Power, M., Gillis, D. E., Maclellan-Peters, J., Alex, M., \& McDonald, C. (2014). Breastfeeding, skin-to-skin contact, and mother-infant interactions over infants' first three months. Infant Mental Health Journal, 35, 51-62.

Bystrova, K., Matthiesen, A. S., Widstrom, A. M., Ransjö-Arvidson, A. B., Welles-Nyström, B., Vorontsov, I., \& Uvnäs-Moberg, K. (2007). The effect of Russian maternity home routines on breastfeeding and neonatal weight loss with special reference to swaddling. Early Human Development, 83, 29-39.

Cai, X., Wardlaw, T., \& Brown, D. W. (2012). Global trends in exclusive breastfeeding. International Breastfeeding Journal, 7, 12.

Chantry, C. J., Eglash, A., \& Labbok, M. (2005). ABM Position on Breastfeeding - Revised. Breastfeeding Medicine, 10, 407-411.

Dragan, W. Ł. (2014). Temperament w pierwszym roku życia. Uwarunkowania genetyczne i środowiskowe [Temperament in the first year of life. Genetic and environmental determinants]. Warszawa: Wydawnictwo Naukowe Scholar.

Dunn, R., Kalich, K. A., Henning, M. J., \& Fedrizzi, R. (2015). Engaging Field-Based Professionals in a Qualitative Assessment of Barriers and Positive Contributors to Breastfeeding Using the Social Ecological Model. Maternal and Child Health Journal, 19, 6-16.

Eidelman, A. I. (2012). Breastfeeding and the use of human milk: an analysis of the American Academy of Pediatrics 2012 Breastfeeding Policy Statement. Breastfeeding Medicine, 7, 323-324.

Flaherman, V. J., Beiler, J. S., Cabana, M. D., \& Paul, I. M. (2016). Relationship of newborn weight loss to milk supply concern and anxiety: the impact on breastfeeding duration. Maternal \& Child $\mathrm{Nu}$ trition, 12, 463-472.

Gartner, L. M., Morton, J., Lawrence, R. A., Naylor, A. J., O'Hare, D., Schanler, R. J., \& Eidelman, A. I. (2005). American Academy of Pediatrics Section on Breastfeeding. Breastfeeding and the use of human milk. Pediatrics, 115, 496-506.

Golańska, Ż. (1994). Karmienie ekologiczne - potrzeba wsparcia [Ecological feeding - the need to suport]. In Z. Kawczyńska-Butrym (Ed.), Wsparcie spoteczne w zdrowiu i chorobie [Social support in health and disease] (pp. 53-59). Warszawa: Centrum Doskonalenia Nauczycieli Średniego Szkolnictwa Medycznego.

Grassley, J. S., \& Nelms, T. P. (2008). Understanding Maternal Breastfeeding Confidence: A Gadame- rian Hermeneutic Analysis of Women's Stories. Health Care for Women International, 29, 841-862.

Haider, S. J., Chang, L. V., Bolton, T. A., Gold, J. G., \& Olson, B. H. (2014). An Evaluation of the Effects of a Breastfeeding Support Program on Health Outcomes. Health Services Research Journal, 49, 2017-2034.

Haroon, S., Das, J. K., Salam, R. A., Imdad, A., \& Bhutta, Z. A. (2013). Breastfeeding promotion interventions and breastfeeding practices: a systematic review. BMC Public Health, 13, 3-20.

Hauck, Y., \& Irurita, V. (2003). Incompatible expectations: The dilemma of breastfeeding mothers. Health Care for Women International, 24, 62-78.

Janiuk, E. (2006). Dlaczego karmienie noworodków przysparza problemów [Why feeding newborns causes problems]. Magazyn Pielęgniarki i Położnej, 3,34 .

Jansen, J., de Weerth, C., \& Riksen-Walraven, J. M. (2008). Breastfeeding and the mother-infant relationship - A review. Developmental Review, 28, 503-521.

Jonas, W., Atkinson, L., Steiner, M., Meaney, M. J., Wazana, A., \& Fleming, A. S.; the MAVAN research team. (2015). Breastfeeding and maternal sensitivity predict early infant temperament. Acta Paediatrica, 104, 678-686.

Karlström, A., Engström-Olofsson, R., Norbergh, K. G., Sjöling, M., \& Hildingsson, I. (2007). Postoperative pain after cesarean birth affects breastfeeding and infant care. Journal of Obstetric, Gynecologic, \& Neonatal Nursing, 36, 430-440.

Kaźmierczak, M. (2015). Oblicza empatii w procesie adaptacji do rodzicielstwa [Faces of empathy in the process of adaptation to parenthood]. Warszawa: Scholar.

Kaźmierczak, M., Kiełbratowska, B., Lewandowska-Walter, A., Michałek, J., \& Błażek, M. (2012). Charakter więzi rodzinnych oraz uwarunkowania ich kształtowania się w sytuacji okołoporodowej [Exploring bonds and its determinants within families with newborn infants]. Psychologia Rozwojowa, 17, 23-39.

Kaźmierczak, M., Kiełbratowska, B., Pastwa-Wojciechowska, B., \& Preis, K. (2013). Couvade Syndrome among Polish expectant fathers. Medical Science Monitor, 19, 132-138.

Kielbratowska, B., Kazmierczak, M., Michalek, J., \& Preis, K. (2015). Temperament and the mother-infant dyad: Associations with breastfeeding and formula feeding with a bottle. Infant Mental Health Journal, 36, 1-8.

Kowalewski, W. (1993). Karmienie piersiq - wybór czy obowiazek? [Breastfeeding - choice or obligation?]. Łódź: Pro-med.

Kushnir, J., Friedman, A., Ehrenfeld, M., \& Kushnir, T. (2012). Coping with Preoperative Anxiety in Cesarean Section: Physiological, Cognitive, and
Breastfeeding and hospital care 
Emotional Effects of Listening to Favorite Music. Birth, 39, 121-127.

Mathews, M. E., Leerkes, E. M., Lovelady, C. A., \& Labban, J. D. (2014). Psychosocial Predictors of Primiparous Breastfeeding Initiation and Duration. Journal of Human Lactation, 30, 480-487.

Mikiel-Kostyra, K. (2003). Odległe skutki zdrowotne sposobu żywienia niemowląt [The distant health effects of infant feeding method]. Medycyna Wieku Rozwojowego, 4, 605-615.

Bogumiła

Kiełbratowska, Justyna Michałek-Kwiecień, Maria Kaźmierczak, Ewa Bandurska

Nehring-Gugulska, M., \& Żukowska-Rubik, M. (2006). Karmienie piersia. Podręcznik [Breastfeeding. Handbook]. Warszawa: National Breastfeeding Committee.

Nissen, E., Uvnas-Moberg, K., Svensson, K., Stock, S., Widström, A. M., \& Winberg, J. (1996). Different patterns of oxytocin, prolactin but not cortisol release during breastfeeding in women delivered by caesarean section or by the vaginal route. Early Human Development, 45, 103-118.

Norris-Grant, D. M., \& Jaggers, C. E. (2014). A Multidisciplinary Approach to Improving Skin-to-Skin Contact Immediately After Birth. Journal of $\mathrm{Ob}$ stetric, Gynecologic, \& Neonatal Nursing, 43, 29.

Phillips, R. (2013). The Sacred Hour: Uninterrupted Skin-to-Skin Contact Immediately After Birth. Newborn and Infant Nursing Reviews, 13, 67-72.

Podolska, M. Z., Bidzan, M., Majkowicz, M., Podolski, J., Sipak-Szmigiel, O., \& Ronin-Walknowska, E. (2010). Personality traits assessed by the NEO Five-Factor Inventory (NEO-FFI) as part of the perinatal depression screening program. Medical Science Monitor Basic Research, 16, PH77-PH81.

Pugh, L. C., Milligan, R. A., \& Brown, L. P. (2001). The breastfeeding support team for low-income predominantly-minority women: a pilot intervention study. Health Care for Women International, 22, 501-515.

Rowu, E. (1995). Emocjonalne zmiany w okresie okołoporodowym - typowe problemy [Emotional changes during the perinatal period - common problems]. In Najlepszy start dla twojego dziecka. Materiaty z Konferencji zorganizowanej przez Stowarzyszenie na Rzecz Naturalnego Rodzenia i Karmienia w Jachrance [The best start for your child. Materials from a conference organized by the Association for Natural Birthing and Feeding in Jachranka]. Warszawa.

Sęk, H., Ścigała, I., Beisert, M., \& Bleja, A. (1992). Subiektywne koncepcje zdrowia. Wybrane uwarunkowania [Subjective concepts of health. Selected determinants]. Przeglad Psychologiczny, 35, 351-363.

Sosnowski, T. (1977). Lęk jako stan i cecha w ujęciu Charlesa D. Spielbergera [Anxiety as a state and trait in terms of Charles D. Spielberger]. Przeglad Psychologiczny, 20, 349-359.

Spatz, D. L., Kim, G. S., \& Froh, E. B. (2014). Outcomes of a Hospital-Based Employee Lactation Program. Breastfeeding Medicine, 9, 510-514.
Spiby, H., McCormick, F., Wallace, L., Renfrew, M. J., D’Souza, L., \& Dyson, L. (2009). A systematic review of education and evidence-based practice interventions with health professionals and breast feeding counsellors on duration of breast feeding. Midwifery, 25, 50-61.

Spielberger, C. D., Gorsuch, R. L., \& Lushene, R. E. (1970). The State-Trait Anxiety Inventory manual. Palo Alto, CA: Consulting Psychologists Press.

Stuebe, A. M., \& Schwarz E. B. (2010). The risks and benefits of infant feeding practices for women and their children. Journal of Perinatology, 30, 155-162.

Taki, M., Mizuno, K., Murase, M., Nishida, Y., Itabashi, K., \& Mukai, Y. (2010). Maturational changes in the feeding behaviour of infants - A comparison between breast-feeding and bottle-feeding. Acta Paediatrica, 99, 61-67.

Tambelli, R., Odorisio, F., \& Lucarelli, L. (2014). Prenatal and postnatal maternal representations in nonrisk and at-risk parenting: exploring the influences on mother-infant feeding interactions. Infant Mental Health Journal, 35, 376-388.

Tsai, T. I., Huang, S. H., \& Lee, S. Y. (2015). Maternal and Hospital Factors Associated with First-Time Mothers' Breastfeeding Practice: A Prospective Study. Breastfeeding Medicine, 10, 334-340.

Wen, L. M., Simpson, J. M., Rissel, C., \& Baur, L. A. (2012). Awareness of Breastfeeding Recommendations and Duration of Breastfeeding: Findings from the Healthy Beginnings Trial. Breastfeeding Medicine, 7, 223-229.

World Health Organization (WHO) \& United Nations Children's Emergency Fund (UNICEF). (1989). Protecting, Promoting and Supporting Breastfeeding: The Special Role of Maternity Services. Switzerland: Genewa.

World Health Organization (WHO) \& United $\mathrm{Na}$ tions Children's Emergency Fund (UNICEF). (1992). Baby Friendly Hospital Initiative Part II: Hospital Level Implementation. Switzerland: Genewa.

World Health Organization (WHO). Switzerland: Genewa. (2015). Infant and young child feeding. Fact sheet $N^{\circ} 342$. Switzerland: Genewa.

Wrześniewski, K., Sosnowski, T., \& Matusik, D. (2002). Inwentarz stanu i cechy lęku STAI. Polska adaptacja STAI [STAI. State-trait anxiety inventory. Polish adaptation]. Warszawa: Psychological Test Laboratory of the Polish Psychological Association. 